\title{
La Educación en la Sociedad del Conocimiento Y DEL RESGO
}

The Education in a Society of Knowledge and Risk

\author{
Elia Mella Garay \\ Universidad de Magallanes \\ Especialista en Evaluación \\ Av. Bulnes 01855 \\ elia.mella@umag.cl
}

Resumen: Los desafíos que la sociedad actual le plantea a la educación se consideran desde la perspectiva de la construcción del conocimiento y de una sociedad democrática, proponiendo el desarrollo de competencias profesionales, que posibiliten que las personas, en el contexto de la sociedad del conocimiento y del riesgo, sean capaces de posicionarse e integrarse en ella, aportando reflexiva y críticamente, a la construcción y desarrollo del ser humano como individuo y al de la sociedad en su conjunto.

Palabras claves: Educación- sociedad del conocimiento- interacción dialógicasociedad del riesgo-competencias.

Abstract: The Challenge that society is facing nowadays is analyzed from two perspectives: from the construction of knowledge and from the point of view of a democratic society. It is proposed the development of fundamental competences that allow people to be personally and profesionally competent in a society of knowledge and risk. People able to take up the challenge contributing reflexively and critically to its construction and development.

Key Words: Education, knowledge society, dialogist interaction, risk society, competence.

\section{INTRODUCCIÓN}

El individuo y la sociedad viven un continuo proceso de interacción que los dinamiza y compromete.

¿Cómo deberían relacionarse las personas con lo que les propone el medio? Para intentar dar alguna respuesta a esta pregunta, es menester revisar la significación que le cabe a la educación en esa relación.

La formación de los futuros ciudadanos que se realiza en forma continua y conjunta entre los distintos agentes educativos desde que el sujeto ingresa a la vida, pone un acento especial en la educación formal a la que le cabe la responsabilidad de brindar numerosas y variadas posibilidades de apropiación del conocimiento a los niños y jóvenes que darán forma a la inmediata estructura societal. 
En este nuevo mundo, de entre todas las tareas que son profesionales 0 aspiran a serlo, la enseñanza es la única a la que se le ha encargado la tarea formidable de crear capacidades y destrezas que permitirán que las sociedades sobrevivan y tengan éxito en la edad de la información (Hargreaves, s/f) ${ }^{1}$.

\section{EL CARÁCTER SOCIAL Y CULTURAL DE LA EDUCACIÓN}

Según Pierre Astolfi, el aprender comprende tres etapas: información, conocimiento y saber, por las que debe transitar aquel que alcance el aprendizaje profundo. Las instituciones educacionales tienen así la tarea de organizar sus procesos de enseñanza y aprendizaje inter y extra aula, considerando estas etapas didácticas. En el fondo de ellas, está el desarrollo de las habilidades intelectuales de los alumnos y alumnas, organizado de manera planificada y consciente para alcanzar en ellos un nivel de reflexión que les permita la autonomía intelectual necesaria para crear y creer en los fundamentos que se constituyan en la base de los continuamente renovados espacios de intervención social.

Los planteamientos que House y Howe (2001) expresan en relación a los evaluadores de programas o políticas educativas son aplicables a los educadores, pues ambos grupos de profesionales abordan tareas que tienen muchos puntos en común. Dicen: "...los evaluadores deben preocuparse de lo que las personas crean tras reflexionar. Este es el sentido más importante de lo que las personas creen realmente frente a las iniciativas de políticas y programas. Una democracia robusta exige que las afirmaciones de valor emerjan mediante la deliberación, conseguida en parte a través del diálogo". (p. 39).

La presencia de la reflexión o deliberación en los sujetos es el sustento de sus creencias y valores, aquellos desde los cuales evaluarán el escenario social en el cual están insertos y en el cual intervendrán a través de sus opiniones fundadas.

Y, enfrentado el sistema educativo, nos preguntamos: ¿Qué condiciones provocan unas afirmaciones de valor para que se conceptualicen bien? Se requieren instancias educativas que permitan la apropiación reflexiva de valores, base de una interacción constructiva con el medio. En la medida que se cumplan esas condiciones, la educación podrá responder al desafío que le plantean los objetivos fundamentales transversales que dicen relación con la continua redefinición y evolución de una sociedad democrática.

El concepto de democracia contempla una forma de gobierno que recoge todos los intereses legítimos para llegar a decisiones de gobiemo. Gutmann (1987) señala otro requisito central de la democracia que consiste en fomen- 
tar la deliberación conjunta de los ciudadanos acerca de materias de política social: "reproducción social consciente".

Existe abundante investigación sobre materiales educativos, libros de texto e incluso acción docente que demuestra que, frecuentemente, se tiende a la reproducción de esquemas, valoraciones e ideologías determinadas que están presentes en el sistema social.

No decimos que todo lo presente se deba eliminar o cambiar definitivamente, es posible que muchos de estos elementos sean los adecuados a un momento 0 grupo social, pero lo que se requiere de la educación y de los educadores es que permitan y posibiliten que los educandos en general, gestores de la sociedad presente e inmediatamente posterior, asuman, gradual y deliberativamente qué elementos, creencias, paradigmas e ideas son aquellas que eligen reproducir en la sociedad que conformarán y desarrollarán. Ese es el sentido de la democracia que debe vivir la educación.

\section{LA EDUCACIÓN EN LA SOCIEDAD DEL CONOCIMIENTO}

La sociedad del conocimiento es la estructura resultante de los efectos y consecuencias de los procesos de mundialización y globalización. Esta estructura dinámica surge de la creación de un sistema de comunicación diverso que se construye desde la tecnología.

En nuestra búsqueda de la verdad y del conocimiento, adherimos a determinadas concepciones, algunas de ellas de carácter interpretativo de la realidad. La interpretación de ésta se puede plantear desde concepciones más o menos extremas, por ejemplo la constructivista radical, que niega la existencia de toda realidad objetiva y que considera que la misma es una construcción humana que depende por completo del acuerdo entre los participantes. (Guba y Lincoln, 1989). Según estos autores, la verdad es el resultado de un consenso entre individuos y grupos, y fuera de esa situación, carece de sentido. Por otra parte, la concepción postmodernista asume el giro interpretativo en una dirección diferente. Según esta concepción, la razón no va a resolver nuestros problemas sino todo lo contrario. Se propone "deconstruir", "desnormalizar" y "desmantelar" los discursos intelectuales que hemos elaborado pues ellos sólo constituyen "regímenes de verdad" en el cual se unen saber y poder para lograr "normalizar" a las personas haciéndolas aquiescentes y "útiles" a la sociedad moderna, (Baynes, K. y otros Eds., 1987).

Asumiendo un enfoque interpretativo que se sitúa en una tercera concepción -democrática deliberativa- que incluye como requisitos la inclusión, el diálogo y la deliberación, podemos asumir que la verdad y el conocimiento se construyen a través del lenguaje en el que se ponen de manifiesto los intereses auténticos de los individuos o grupos, por medio del 
diálogo crítico. En la medida que el lenguaje se va transformando anulando formas y estilos anteriores, reflejo de una verdad anterior, también va generándose otra realidad que se estructura y organiza a partir de las lógicas, intencionalidades y valoraciones de quienes se apropian de este nuevo lenguaje. Por un lado, la concepción que asumimos para entender la construcción de la realidad y por otro, la comprensión de la realidad construida por el lenguaje de las nuevas tecnologías, nos hace percibir la sociedad emergente, con un sentido de red y características que hacen que la relación dialógica se manifieste de un modo diferente. Surgen entonces:

- Una nueva forma de concebir el tiempo y el espacio, haciendo que estos elementos básicos para la constitución del ser social se configuren desde otra lógica referida al tiempo y al espacio, ya que los participantes en el diálogo pueden comunicarse y construir relación desde diversos lugares y momentos.

- Se asigna y reconoce mayor valor para la información, transformándola en un elemento clave de realización personal y profesional, sin la cual los sujetos no pueden participar activamente en los procesos de construcción social, desde las variadas perspectivas en que ello es posible.

- Se reconoce una tendencia hacia la inmaterialización de los procesos laborales, permitida e impulsada por el desarrollo tecnológico: negocios y oficinas virtuales, comunicaciones en red que de alguna manera cambian las relaciones laborales tradicionales donde existía un lugar físico específico y personas que interactuaban presencialmente en ese espacio.

- Dependencia y en algunos casos subordinación de las comunidades menos desarrolladas desde el punto de vista tecnológico ante aquellas que han logrado mayor avance; mientras ciertas comunidades están en proceso de alfabetización en el ámbito del desarrollo tecnológico, otros se encuentran en una etapa de perfeccionamiento avanzado, que les permite ir construyendo nuevos conocimientos, nuevas realidades y nuevas sociedades con organizaciones y realizaciones más efectivas y veloces lo que les da una ventaja en el aumento de la productividad económica, social y cultural.

La globalización y mundialización como procesos que se han ido desarrollando a partir de fenómenos de apertura, de rápido intercambio, de información que fluye a mayor velocidad, de explosiones comunicacionales y de avances tecnológicos, ha acarreado consecuencias económicas, sociales, culturales y políticas, pero el soporte societal básico, que se transforma, pero no se modifica estructuralmente, nos pertenece a las personas, quienes a través de esta participación crítica y deliberativa a la que hemos hecho referencia pueden intervenir y moldear la forma e intensidad en que estos procesos de cambio afectan la vida del hombre. De ese modo se produce el tránsito hacia la sociedad del conocimiento que surge cuando dichos efec- 
tos aparejados a un desarrollo explosivo de la tecnología, adquieren la fuerza y la organización necesaria que va originando un nuevo lenguaje, que no debe dejar de ser herramienta del diálogo crítico, elemento esencial que permite la generación de un cambio estructural en las concepciones y paradigmas que modifican los pilares de una sociedad y abren paso a la configuración de otra, en que el conocimiento construido se va legitimando y las potencialidades de otras construcciones abren nuevas visiones de organización, funcionamiento y desarrollo.

En esta perspectiva de dinamicidad y transformación, se requiere educar un ser social que esté preparado para enfrentarla, con una nueva competencia que denominamos "Visión relacional" o "Visión sistémica", entendida como aquel conjunto de habilidades que articuladamente permiten al sujeto darse cuenta o tomar conciencia del estado del arte del medio, descubriendo su sentido de pertenencia, la finalidad de su quehacer y las necesidades de transformación que requiere para equilibrarse y reequilibrarse continuamente, tanto en conocimientos, como en comportamientos y actitudes, lo que se vincula con la capacidad de seguir aprendiendo siempre, sustentada en un logrado "aprender a aprender" (V. Alvarado, com. pers.).

La visión relacional compromete habilidades de: focalización del ser y estar en un determinado ámbito, descubrimiento de factores y variables intervinientes en sí mismo y en el entorno, relación sistémica de dichos factores, evaluación de sus fortalezas y debilidades para desempeñarse, mediación sociocultural, planeación personal y colectiva en escenarios diversos. Esta visión relacional potencia y enriquece la deliberación, entendida como la tercera etapa para alcanzar la construcción de la realidad en la concepción democrática deliberativa.

\section{LA EDUCACIÓN EN LA SOCIEDAD DEL RIESGO}

La nueva estructura societal, denominada por algunos autores como sociedad del riesgo, se caracteriza por la inseguridad que otorga el desdibujamiento cada vez más profundo de las intervenciones humanas y las relaciones causa efecto en los sistemas de producción, no sólo materiales, sino también financieros, de información y culturales.

En este contexto, surgen cambios significativos que implican un desplazamiento desde la lógica de reparto de la riqueza a una lógica de reparto del riesgo, tal como lo expresa el autor Beck, Ulrich (1998): "En la medida en que se presentan estas condiciones, un tipo histórico del pensamiento y de la actuación es relativizado o sustituido por otro. El concepto de sociedad industrial o de clases (en el sentido más amplio de Marx y Weber) giraba en torno a la cuestión de cómo se puede repartir la riqueza producida socialmente de una manera desigual y al mismo tiempo legítima. Esto coincide 
con el nuevo paradigma de la sociedad del riesgo, que en su núcleo reposa en la solución de un problema similar y sin embargo completamente diferente. ¿Cómo se pueden evitar, minimizar, dramatizar, canalizar los riesgos y peligros que se han producido sistemáticamente en el proceso avanzado de modernización y limitarlos y repartirlos allí donde han visto la luz del mundo en la figura de efectos secundarios latentes, de tal modo que ni obstaculicen el proceso de modernización, ni sobrepasen los límites de lo soportable (ecológica, médica, sicológica, socialmente)?." (p. 238).

El planteamiento de Beck, nos alerta sobre los resultados que los procesos de modernización acarrean y pueden seguir acarreando, masificados exponencialmente en la población mundial. Efectos que impactan los ámbitos científico, tecnológico, educativo, económico, ecológico, ideológico, entre otros, y que implican que aunque la lógica del desenvolvimiento del proceso ha sido la misma a nivel mundial, sin embargo la dinámica y los resultados no han sido similares desde la perspectiva de la equidad. Si nos situamos en el ámbito educativo, la misma se concibe hoy como una inversión social y se plantea desde la lógica de, a mayor educación, mayor nivel de producción, generando una serie de iniciativas de reformas que pretenden, a través de programas pedagógicos, tecnológicos, de infraestructura y otros, lograr la esperada equidad social, que tampoco es posible de alcanzar en los niveles planeados, debido a la cantidad y variedad de factores sociales, culturales o económicos, que en esta sociedad de riesgo, inmanejable en la mayoría de sus ámbitos de acción, determinan los resultados educativos.

La complejidad que posee una sociedad de riesgo sumada a la debilidad en las estrategias para su manejo, se debe, en parte, a la mirada parcial y poco transversal que se asume para reconocer e investigar los procesos científicos, tecnológicos, sociales y culturales. La uniformidad de la distribución, la excesiva racionalización, la tendencia hacia la búsqueda de objetividad y la sobrevaloración de lo cuantitativo respecto a lo cualitativo, compiten con el espacio para la existencia y aporte de la intuición, el reconocimiento de la diversidad, la valoración del ensayo y error, todos elementos y procesos necesarios para desempeñarse en una sociedad del riesgo y para la búsqueda de soluciones a los problemas emergentes.

Para que la sociedad del riesgo se transforme en un espacio que permita una experiencia de vida sostenible y en desarrollo, se requiere una transformación de la conciencia individual y colectiva, significa, tal como lo expresa el autor Ulrich, Beck (1998) "...en las situaciones de clases y capas, el ser determina a la conciencia, mientras que en las situaciones de peligro, la conciencia determina al ser. El saber adquiere un nuevo significado político. Por consiguiente hay que desplegar y analizar el potencial político de la sociedad del riesgo en una sociología y en una teoría del surgimiento y difusión del saber de los riesgos" (p.238). El saber, la información y la capa- 
cidad de manejarla se transforman hoy en armas poderosas para la realización personal y el desarrollo social.

Nos demandan estas y otras conceptualizaciones relacionadas con las nuevas demandas de la globalización de los procesos culturales y económicos y la sociedad de la información. En su ponencia "El desarrollo profesional de los docentes", Avalos (2000) expresa: "Los educadores además de lograr los aprendizajes esperados de la escuela, deben manejar propuestas curriculares hasta cierto punto ambiguas y con esquemas conceptuales muy diferentes a los anteriores, y estimular el desarrollo e habilidades cognitivas de muy distinto orden a lo que estaban acostumbrados."

Frente a esta realidad, la educación debe asumir entonces, la misión de cultivar y potenciar en los sujetos, nuevas competencias que hemos identificado como "Tolerancia a la incertidumbre" y "Administración del riesgo". Ambas se entienden como un conjunto de habilidades y capacidades desarrolladas que le permitan al sujeto anticipar los desequilibrios y cambios que una posible dinámica o intervención personal, social o tecnológica traería consigo en un determinado escenario, controlar la ansiedad que este nuevo panorama le produce dándose el tiempo y el espacio para descubrir 0 elaborar estrategias de acomodación a partir de las cuales poder tomar las mejores decisiones en esas circunstancias. Estas competencias significan, por un lado, aplicarse profunda, consciente y críticamente en el medio social en que interviene y se desarrolla y por otro, mantenerse en un estado de alerta y búsqueda permanente, para descubrir las señales que indican cambios que podrían afectar sustancialmente su ser y sus posibilidades de realización personal y social con el fin de estar preparado para darles respuesta. Esta apertura y supervisión constante de su entorno es la que le permite anticiparse y reconvertir sus intereses y capacidades y adoptar una posición que le posibilite enfrentar adecuadamente el desequilibrio, sostenerlo y por tanto administrar el riesgo que éste involucra para su desempeño social.

La toma de conciencia frente a lo que vivimos y ante lo que se avecina, marcado por las señales que podemos leer en el entorno, será el desafío que los seres de este momento histórico deberán enfrentar; para ello, sus armas seguirán siendo aquellas que les debe entregar la educación: capacidad de asumir su realidad, reflexionar críticamente sobre ella, decidir con autonomía intelectual y sustentado en valores, construidos social y democráticamente. 


\section{NOTAS}

${ }^{1}$ citado en "El desarrollo profesional de los docentes. Proyectando desde el presente al futuro". Beatrice Avalos. Seminario sobre prospectivas de la Educación en la Región de América Latina y el Caribe, UNESCO, Santiago, 2000

\section{REFERENCIAS BIBLIOGRÁFICAS}

Alvarado, V. et al, 2003

Astolfi, J.P. 1997

Avalos, B. 2000

Beck, Ulrich 1998

Baynes, K y otros (Eds.) 1987

Guba, E. G. y Y. S: Lincoln. 1989

Gutmann, A. 1987

House, E. R. y K. R, Howe. 2001
Enfoques socioculturales de la educación. Documento mimeografiado. Universidad de Magallanes, $11 \mathrm{pp}$.

Aprender en la escuela. Editorial Dolmen, Santiago, $213 \mathrm{pp}$.

El desarrollo profesional de los docentes. Proyectando desde el presente al futuro. En: Ponencia presentada en Seminario sobre Prospectivas de la Educación en la Región de América Latina y el Caribe, UNESCO, Santiago de Chile.

La sociedad del riesgo. Hacia una nueva modernidad. Ed. Paidós, Barcelona. Texto reproducido en: Raúl Clerc (ed.) Debate Contemporáneo en Educación II. (Magister en educación a distancia. Universidad Arcis, pp. 287-308).

Questions of method: An interview with Michael Foucault. En: K. Baynes, Bohman, J. y Mc Carthy, T. (Eds.), After philosophy: End or transformation, MIT Press, Cambridge.

Fourth generation evaluation. CA: Sage. Newbury Park.

Democratic education. NJ. Princeton. Princeton University Press. Trad. al castellano: La educación democrática. Una teoría política de la educación, Paidós, Barcelona, 2001.

Valores en evaluación e investigación social. Ed. Morata, Madrid, $257 \mathrm{pp}$. 